This item was submitted to Loughborough's Research Repository by the author.

Items in Figshare are protected by copyright, with all rights reserved, unless otherwise indicated.

\title{
Establishing intellectually impaired victims' understanding about 'truth' and 'lies': Police interview guidance and practice in cases of sexual assault
}

\section{PLEASE CITE THE PUBLISHED VERSION}

https://doi.org/10.1093/applin/amy023

\section{PUBLISHER}

(C) The Authors. Published by Oxford University Press (OUP)

\section{VERSION}

AM (Accepted Manuscript)

\section{PUBLISHER STATEMENT}

This is a pre-copyedited, author-produced version of an article accepted for publication in Applied Linguistics following peer review. The version of record RICHARDSON, E., STOKOE, E. and ANTAKI, C., 2018.

Establishing intellectually impaired victims' understanding about 'truth' and 'lies': Police interview guidance and practice in cases of sexual assault. Applied Linguistics, 40(5), pp. 773-792 is available online at: https://academic.oup.com/applij/article/40/5/773/5035076 and https://doi.org/10.1093/applin/amy023.

\section{LICENCE}

CC BY-NC-ND 4.0

\section{REPOSITORY RECORD}

Richardson, Emma, Elizabeth Stokoe, and Charles Antaki. 2018. "Establishing Intellectually Impaired Victims' Understanding About 'truth' and 'lies': Police Interview Guidance and Practice in Cases of Sexual Assault". Loughborough University. https://hdl.handle.net/2134/32786. 


\title{
Establishing intellectually impaired victims' understanding about 'truth' and 'lies': Police interview guidance and practice in cases of sexual assault
}

Emma Richardson, University of Manchester

Oxford Road, Manchester, M13 9PL.

Elizabeth Stokoe, Loughborough University

Epinal Way, Loughborough, LE11 3TU.

Charles Antaki, Loughborough University

Epinal Way, Loughborough, LE11 3TU.

\begin{abstract}
Effective police interviews are central to the justice process for sexual assault victims, but little is known about actual communication between police officers and witnesses, nor about the alignment between guidance and real practice. This study investigated how police officers, in formal interviews, follow 'best evidence' guidance to obtain victims' demonstrable understandings of 'truth and lies'. We conducted qualitative conversation analysis of 20 evidentiary interviews between police officers and victims who were 'vulnerable' adults, or children. Analysis revealed that interviewers initiated conversation about truth and lies inappropriately in three ways: 1) by eliciting confirmations rather than demonstrations of understanding; 2) by eliciting multiple demonstrations and confirmations of understanding, or 3) by re-introducing 'truth and lies' conversations at incorrect points in the interview. Both 2) and 3) imply prior or forthcoming dishonesty on the part of the victim. In the context of encouraging victims to report sexual assault, and achieve justice, the paper
\end{abstract}


reveals potential communicative barriers in which victims - or their evidence - may be discredited right at the start of the process.

KEYWORDS: Sexual assault, rape, police interviews, communication guidance, victims, intellectual impairment 


\section{Introduction}

When police deal with 'vulnerable' people (children, or adults with intellectual impairments) who may have been sexual assaulted or raped, they are meant to take extra care in their formal, recorded interviews. 'Best practice' guidelines recommend that they establish that alleged victims understand what it means to report their experiences honestly and understand, as the guidelines put it, the difference between 'truth and lies'. This article examines the guidelines with respect to how interviewers ought to establish such understandings, and what, in fact, actually happens.

\section{Sexual assault and the social problem of rape reporting}

The interviews we analyse take place in a broader cultural context of rape underreporting and even lower rates of charge and conviction (see Krahé, 2016). We know that the causes of underreporting and, subsequently, low prosecution and conviction rates, include the prevalence of 'rape myth' - “prejudicial, stereotyped, or false beliefs about rape, rape victims, and rapists" (Burt, 1980, p. 217) - pervasive in public and private discourse (Armstrong, Hull and Saunders 2015). We also know that rape myth pervades legal institutions - the police and courts - in the way alleged victims are characterized, interviewed and cross-examined, and in the way cases are summarized by judges (e.g., Ehrlich 2001; Drew 1992; Temkin, Gray and Barrett, 2018). Indeed, false assumptions about rape and sexual assault may emerge at the outset of any legal process, in initial police interviews, as MacLeod (2010) graphically illustrates in a study of recordings of interviews with a number of women alleging rape. Achieving justice in cases of sexual assault is a challenge for criminal justice systems in the battle against attrition, where the majority of reported rape cases fail to reach trial (Burman, Kelly and Lovett 2009). In the UK, the Crown Prosecution 
Service (2016) reports that it is now prosecuting and convicting a record number of sexual offence cases than in any previous year, but there remains a huge gap in experienced versus recorded sexual offences in England and Wales.

The first stage in obtaining justice is reporting the offence to the authorities. In the UK, the police act as 'gatekeepers' to justice for victims; a crime is reported, police then gather evidence and decide whether or not to 'detect'. The reporting and evidence gathering stage is therefore highly consequential to justice being obtained. Due to the nature of sexual offences, victims face numerous barriers to disclosure; a non-exhaustive list of these barriers includes "a fear of being disbelieved; fear of retribution by the offender or others connected to the offender; feelings of shame; embarrassment; living in an isolated environment; fear of being blamed; lack of confidence or trust in the legal system; and lack of confidence or trust in police" (Taylor and Gassner 2010: 241).

As noted previously, barriers to disclosure are linked to rape myth culture (Lonsway and Fitzgerald 1994; see also Hayes, Lorenz and Bell 2013), which trivialises sex offences and shifts blame onto the victim (Burt 1980). The construct of 'real rape' - that sexual attackers are unknown to their victim, use a weapon and inflict serious injury (Estrich 1987) also works to erode the perceived severity of sexual offences committed by someone known to the victim. This can leave victims unsure about the status of their assault and questioning whether or not others will view it as rape (Daly and Bouhours 2010). Furthermore, old and new media fuel rape myths by disproportionality covering stories such as false rape allegations (see Armstrong, Hull and Saunders 2015). Police, judges, juries, and members of the general public are all exposed to rape myths which, in turn, contribute to negative attitudes towards victims (CWCJS, 2009) and inform police decision-making around credibility of a witness (Jordan 2004; Parratt and Pina 2017). 


\section{Sexual assault and intellectual impairment}

Research suggests that vulnerable victims or witnesses, particularly those with intellectual impairment or disability, are more likely to be sexually abused or assaulted than those without (e.g., McEachern 2012; Petersilia 2001). Yet adults with intellectual disability are even less likely to speak out about their abuse (Brown et. al. 1995). Of those that do, their cases rarely appear in court (Kebbell, Hatton, Johnson and O'Kelly 2001). Adult victims of rape with learning disabilities or psychiatric problems are, then, over-represented in terms of cases that 'drop out' of the system (Lea, Lanvers and Shaw 2003).

There are a variety of reasons why vulnerable witnesses face additional challenges in obtaining justice, to those without vulnerability (Kebbell and Hatton 1999). Some research has shown that these witnesses may have memory limitations, be more suggestible, may yield more to leading questions, and may distort or fabricate material when there are gaps in knowledge (Clare and Gudjonsson 1993; Gudjonsson and Henry 2003). While the implication is that their evidence is less robust than that given by people without such challenges, individuals with intellectual disabilities may be perceived as unreliable witnesses (Beail 2002). Yet these witnesses have also been found to be perceived by jurors as more credible, honest and less capable of fabricating a sexual abuse accusation than those without disability (Bottoms et. al. 2003).

\section{Police interviewing in sexual assault cases with vulnerable witnesses}

For victims of sexual assault to achieve justice, they must be interviewed by police, as their statements form crucial evidence in court (Kebbell and Milne 1998). While it is clearly essential to obtain complete and accurate accounts of the incident from victims (Cederborg and Lamb 2008), obtaining such evidence from victims with intellectual disabilities is a recognised challenge for the police. In 2001, in attempt to tackle such challenges, the Youth 
Justice and Criminal Evidence Act introduced special measures for vulnerable victims and witnesses to enable the best conditions to provide evidence (see Cooke and Davies 2001). The document Achieving Best Evidence in Criminal Proceedings: Guidance for Vulnerable and Intimidated Witnesses ('ABE') provides guidance on the implementation of special measures, specifically identifying the needs of the vulnerable witness or victim, planning and preparing for the interview, conducting the interview, and preparing victims for the court process. While ABE is not enforced legally, it is used widely, and urges best practice for those conducting video-recorded interviews with vulnerable adults and children (Bull 2010).

One of the challenges for police officers is to translate $\mathrm{ABE}$, and other guidance for interviewing witnesses, into practice. Many researchers have shown that, when practitioners attempt to turn written guidance, training materials or scripted questions into actual interaction, the ensuing practices vary from those idealised versions (e.g., HoutkoopSteenstra and Antaki 1997; Maynard and Schaeffer 2006; Stokoe 2013). We know very little about how ABE guidance is deployed in real-time interviews, and whether or not it hinders or facilitates evidence-giving in cases of sexual assault. Therefore, this paper examines interviews with vulnerable victims, to show if, and how, police officers align their practice to ABE guidelines. We focus specifically on one requirement of the guidance: 'Oaths and the importance of telling the truth'. In this phase, police officers assess whether or not witnesses are able to differentiate between, and understand the importance of, telling the truth and telling a lie. We will show in our analysis that this particular requirement generates problems for evidence-gathering and for victim credibility. We consider the interactional practices involved in this task, and reveal the implications its realization may have in the quest for justice for this group. 


\section{Data and method}

The data come from a wider project examining police interviews with vulnerable witnesses, in collaboration with a UK police force. Following data protection and police and university research ethics, we were provided with 20 archived video recorded police-witness interviews. Of the 20, 18 were usable. We excluded one because it was incomplete, and one because we did not have access to appropriate language translation services. We anonymized the recordings aurally and visually on site at the police station prior to removal and storage on an encrypted hard drive. All names, including place names have been replaced by pseudonyms. Two men and sixteen women interviewees were aged between 12 and 35 . We note that the term 'witnesses' is the term used in the ABE guidance to refer to the alleged victims. We were provided with brief details about the intellectual impairments of witnesses (e.g., 'Autism', 'learning difficulties') and the offence and the outcome for each case (e.g., 'Filed undetected, insufficient evidence, no CPS'). Out of 18 cases, only three resulted in a charge being made, and, of these, two perpetrators were imprisoned and one was found not guilty. The interviews featured the 'significant' or 'key' witness, who, under the ABE guidelines, should usually be video-recorded to increase the quality of information. For vulnerable or intimidated witnesses, an application can be made for video-recorded interviews to be used as 'evidence-in-chief' in the court room, along with other options for special measures (e.g., live

video link). Therefore, the recorded conversations are highly consequential for the pursuit of the case through the criminal justice system.

The data were anonymized and then transcribed using Jefferson's (2004) system for conversation analysis (CA). CA has been used extensively to examine how practitioners deliver their services in a wide variety of environments (see Antaki 2011). CA examines the overall structure of interaction, in terms of its constituent actions, as well as the specifics of, 
and patterns in, turn design (how a turn of talk is designed to do something), turn-taking (who talks when), action formation (how actions are formed within and across turns of talk), and sequence organization (how actions are organized in a sequence) (see Schegloff 2007). For the purposes of the current paper, we examined opening sequences in which officers introduced the truth/lies project, and show how communication guidelines were (not) translated into real talk.

We cannot assume any witness communication difficulties, especially based on the limited description of the intellectual impairment of the witnesses. An intermediary is used with 4 of our 18 interviews; their role is to assist with communication where there might be issues in identifying and reporting a problematic question. We indicate in the transcript when an intermediary is actively participating to facilitate the interview.

\section{Analysis}

ABE guidelines state that not all vulnerable adult witnesses should be asked about truth and lies. When questions are asked, certain witnesses should demonstrate their understanding. The ABE guidelines are presented for the reader:

\section{“Certain Vulnerable Adult Witnesses}

3.22 In cases where discussion of truth and lies is appropriate, it is important to demonstrate that the witness understands the difference between the two. The witness could be asked to give examples of truth and lies. If this is not possible, the interviewer can ask some questions about this difference. If such questions are asked, they should follow the guidance set out elsewhere on styles of questioning, and focus on the intention to deceive rather than mere mistakes. After such questions, it is appropriate to conclude with a statement like: 'Please tell me all you can remember 
about what happened. Don't make anything up or leave anything out. It is very important to tell the truth." "(U.K. Ministry of Justice, 2011, p.73)

In half of the interviews there was no explicit exchange about honesty or truth telling. For those that did include it, we analyse:

1. How officers elicit from witnesses a demonstration of the difference between a truth and a lie;

2. How they formulate the difference, or a previous conversation about difference that is not recorded, for witnesses to confirm;

3. How they pursue the witnesses' understanding in an interrogative manner via multiple demonstrations and confirmations; and,

4. How witnesses and police officers reintroduce truth telling episodes in other, inappropriate, parts of the interview, and the consequences of doing so. According to ABE, 'oaths and the importance of telling the truth', which we refer to as 'truth and lies sequences', should follow formal preliminaries about the recording process and who is present, but not occur elsewhere.

\section{Eliciting a demonstration of the difference between a truth and a lie}

In Extract 1, we present an example of the check on understanding of 'truth' and 'lies' being accomplished appropriately, and aligned to the guidance in $\mathrm{ABE}$, in which $\mathrm{W}$ demonstrates their understanding. In each extract, $\mathrm{P}$ is the interviewing officer, and $\mathrm{W}$ is the witness.

Extract 1: Interview 1

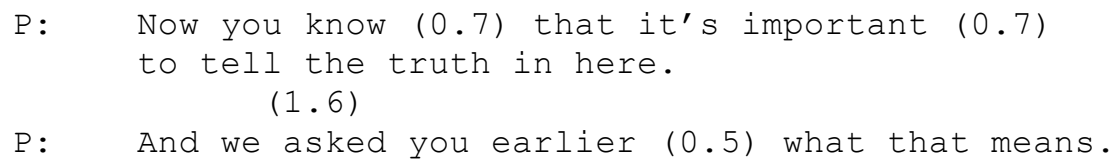




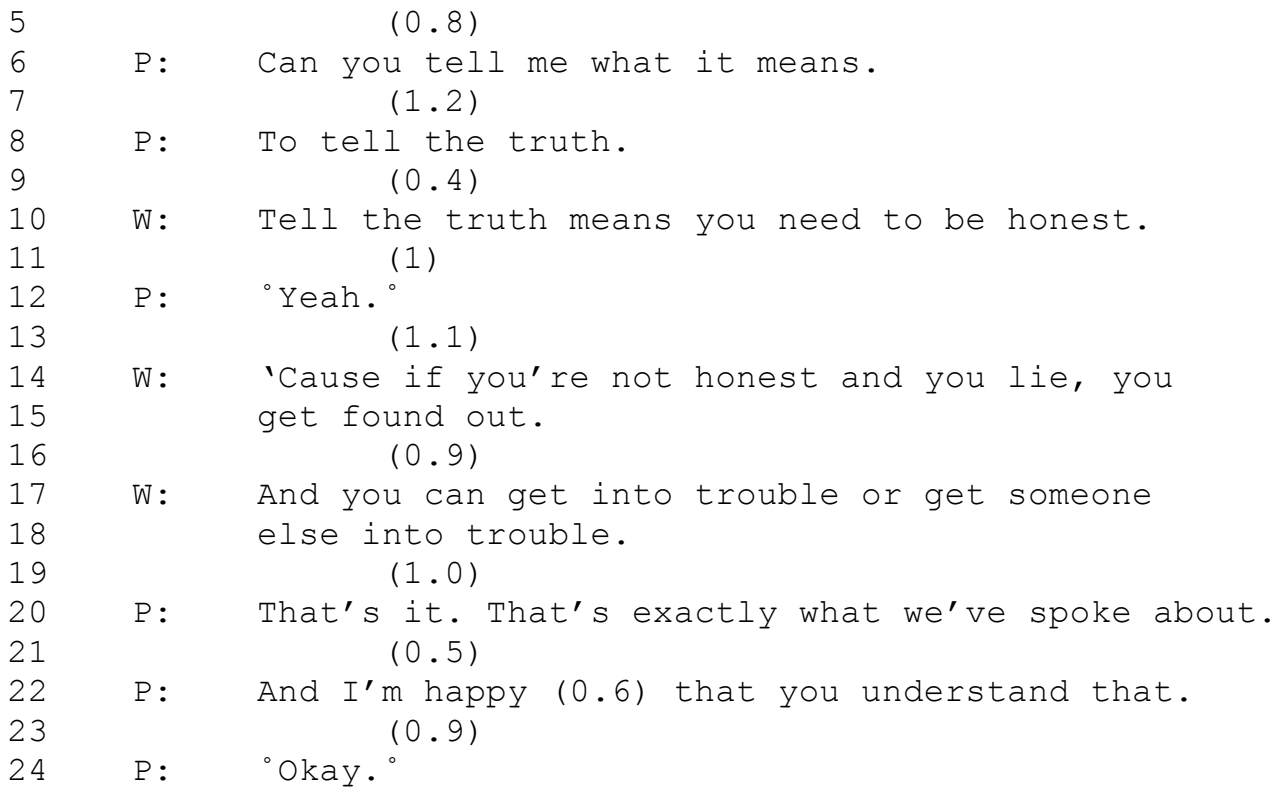

At line 4 it is revealed that the witness has been asked earlier (outside of the formal recorded interview) what 'that' means; indexing 'tell the truth'. The police officer requests that the witness formulate verbally what "it means", which is further expanded at line 8 "to tell the truth" after a gap in which W does not respond. Across several turns (lines 10-18), the witness formulates their understanding of what it means to tell the truth. Unprompted by $\mathrm{P}, \mathrm{W}$ expands her initial response ("Tell the truth means you need to be honest") to describe what might happen if "you tell a lie" (lines 14-18). This accomplishes the goal of eliciting, for the record, a demonstration of the witnesses' understanding; note P's positive assessment (Lines 20-22). There is no further expansion and $\mathrm{P}$ closes the sequence.

Having presented an example of how interviewers elicit demonstrations that witnesses understand the difference between 'truth and lies' appropriately, aligned with ABE guidance, we move on to examine how deviation from the guidelines can happen.

\section{Asking witnesses for brief confirmations of interviewer-formulated demonstrations}

In Extract 2, the interviewer introduces the 'truth and lies' conversation in a different way. 


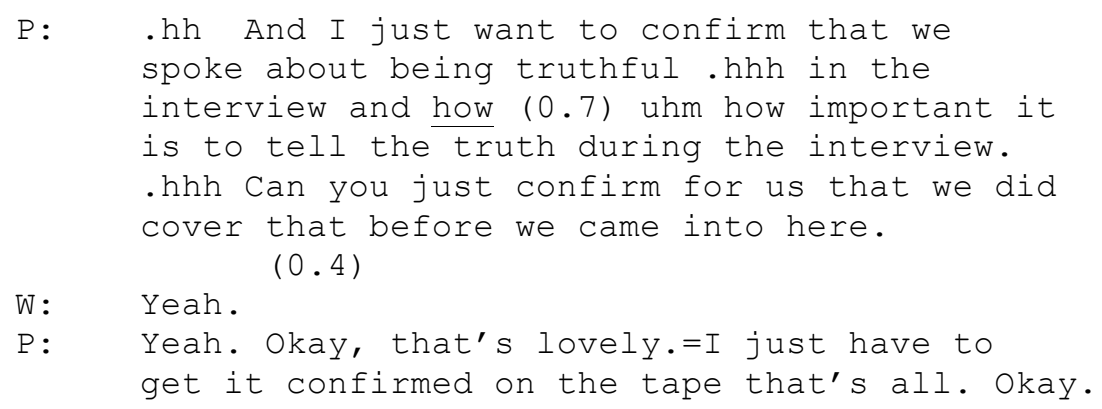

In contrast to Extract 1, P formulates a summary (lines 1-4) of a conversation that the police officer and the witness have had prior to the video recorded interview, for $\mathrm{W}$ to confirm (line 8). This informs any future audience of the recording that it has been deemed appropriate to have this conversation around truth telling. But what is not present is a witness demonstration of the difference between a truth and a lie, or an understanding of the implications of lying. $\mathrm{P}$ provides an account for requiring an on-the-record confirmation ("I just have to get it confirmed for the tape, that's all". The repeated use of 'just' (lines 1, 5 and 9) minimises the importance of this action and its impact on the progression of the interview.

Extract 2 is an example of how officers may deviate from the guidelines, by eliciting a confirmation rather than a demonstration of understanding from witnesses. The same thing occurs in police interviews with suspects, in which officers may elicit demonstrations of suspects' understandings of their legal rights, or formulate their rights for suspects to confirm (Stokoe 2013). In Extract 2, P has translated the ABE guidelines into a different action than we saw in Extract 1. While the interviewee has co-operated to confirm that they will tell the truth, it is done briefly as a formality for the tape. Extract 3 is similar; RI is a 'Registered Intermediary' who is present to support the witness in providing as complete, accurate and coherent account of the event as possible. The use of an intermediary is appropriate when the person being interviewed may be unable to recognise a problematic question, or reluctant to say so to a person in a position of authority (CPS, 2017). 


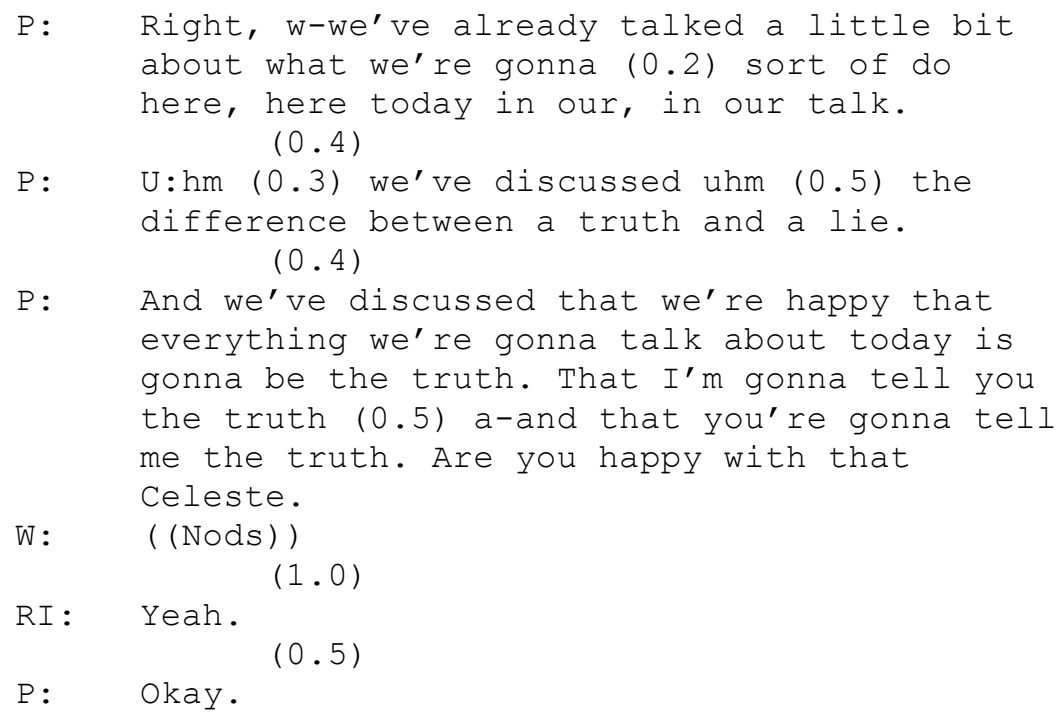

Here, $\mathrm{P}$ formulates a previous and unrecorded conversation about truth and lies for $\mathrm{W}$ to confirm. A verbal demonstration does not occur. However, P formulates a reciprocal agreement that both parties will 'talk about the truth'. W confirms with a gesture (line 14) and the AA formulates W's gesture to confirm verbally at line 16, "yeah". The police officer closes the sequence and moves onto the next action.

In Extract 4, $\mathrm{P}$ formulates a previous conversation, but $\mathrm{W}$ provides neither verbal nor embodied confirmation.

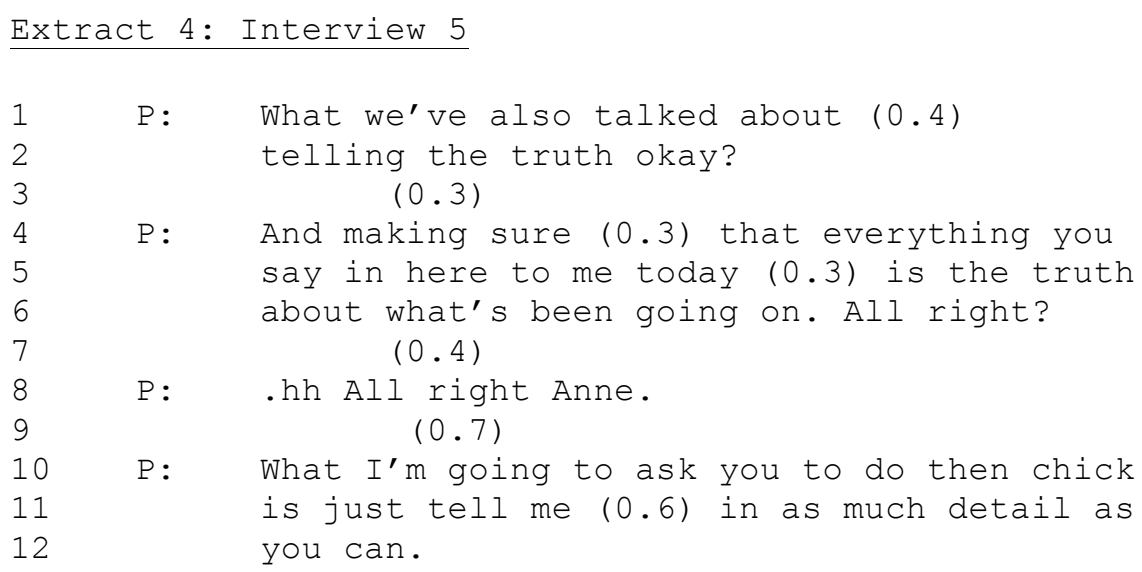


Like previous extracts, $\mathrm{P}$ initiates the topic of telling the truth for the tape, formulating a prior but unrecorded conversation. Even though there are gaps for a confirmation to take place (e.g., lines 3 and 7), both audio and video recording reveals no explicit confirmation from W; the interview proceeds on the basis of a passive or implicit agreement to tell the truth.

In this section, we have seen how interviewers incorporate 'truth and lies sequences' into the larger project of negotiating the 'ground rules'. The ABE guidelines state that "In cases where discussion of truth and lies is appropriate, it is important to demonstrate that the witness understands the difference between the two" (p.73, emphasis added). As the goal is to elicit a demonstration, then, as part of evidence-giving and relevant to later court proceedings, then this practice does not produce such a demonstration. This may not be in the best interests of the victim; if they do not, for the record, display their understanding of 'truth and lies', subsequent evidence may be regarded as less robust.

In the next section, we see further instances of practices that do not align with $\mathrm{ABE}$ guidance.

\section{Repeated and multiple demonstrations and confirmations of understanding}

In Extract 5, we join the interview after the mandatory preliminaries have been completed.

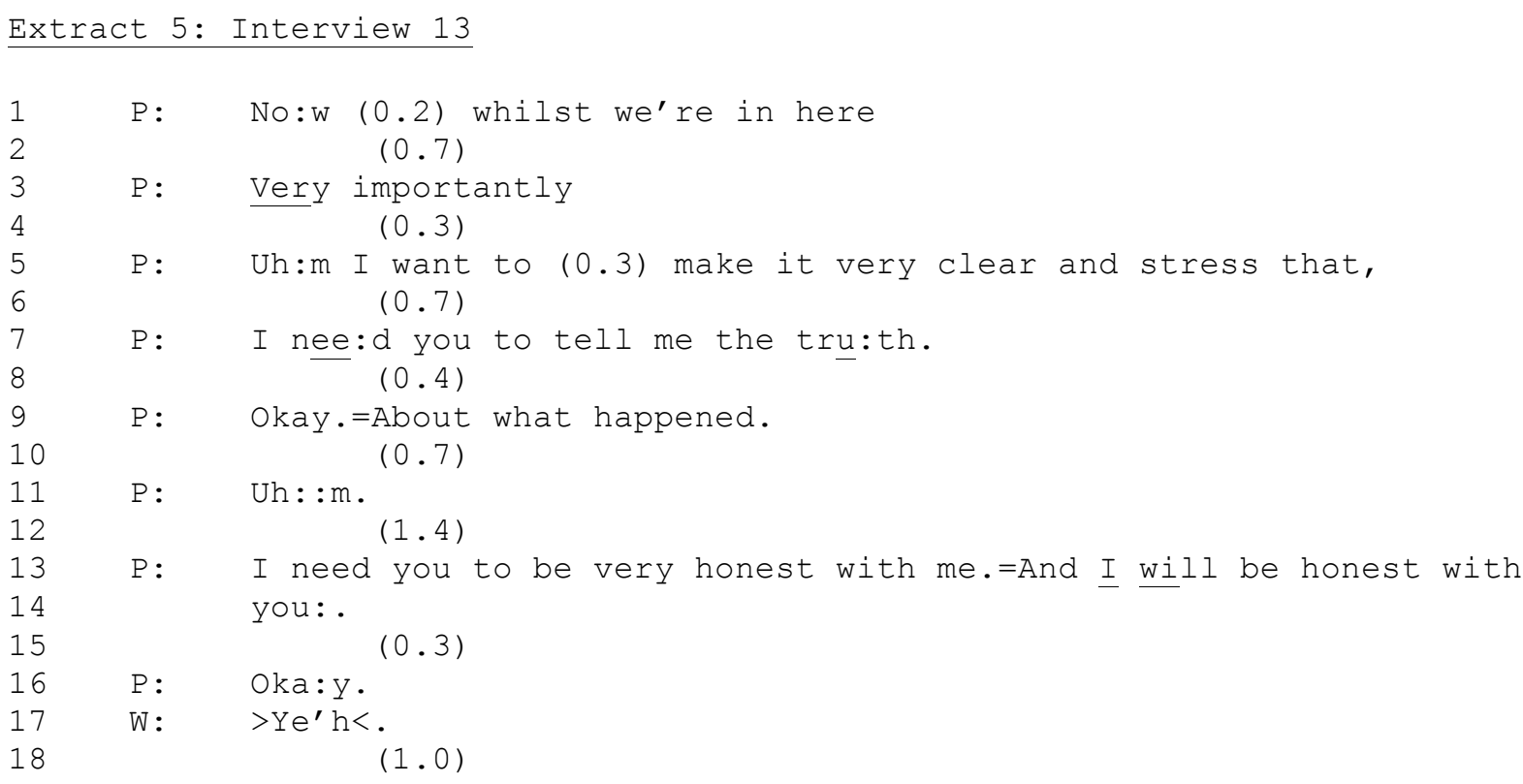


The ABE guidance suggests that statements like, "Please tell me all you can remember about what happened. Don't make anything up or leave anything out. It is important to tell the truth." (3.22, p.73, italics added) are appropriate. In Extract 5, P builds an extended sequence with additional hyperbolic components - multiple adverbs ("very") and imperative verbs ("need") - not seen in previous examples ("I want to (0.3) make it very clear and stress that I nee:d you to tell me the tru:th.”). This extract prefaces a further extensive and expanded sequence of talk about 'truth telling'. Extract 6 occurs about 80 seconds later in the interview.

Extract 6: Interview 13 cont.

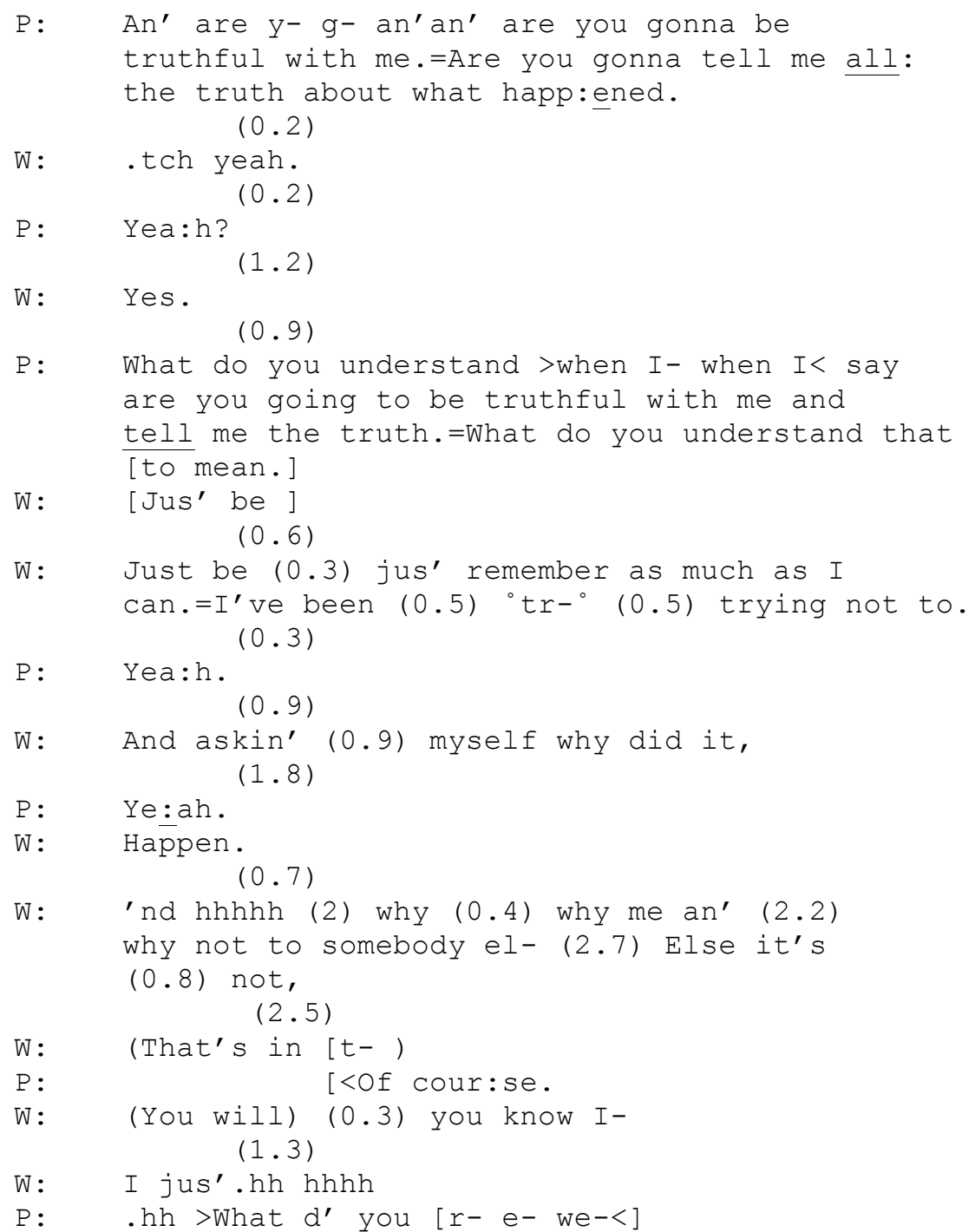




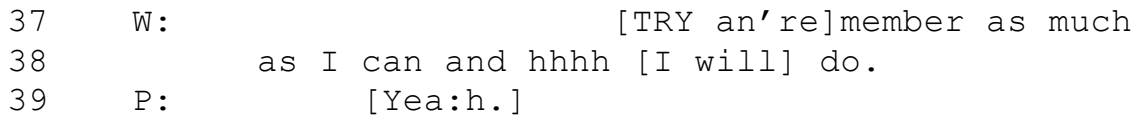

As the sequence unfolds, $\mathrm{P}$ does elicit a demonstration of understanding from $\mathrm{W}$ (lines 15-18; 22, 25, 27-38). However, unlike earlier extracts, $\mathrm{P}$ asks the witness interrogative questions ("are you gonna be truthful with me"; "Are you gonna tell me all the truth about what happened"), embedded the imperative-laden and hyperbolic prefaces seen in Extract 5. P's approach to 'truth and lies' has a different and moral project than earlier examples, in which officers simply state the importance of telling the truth. The structure of Extract 6 looks more like a suspect interview, where police officers use follow-up questions, to pursue any incomplete or inconsistent answers rather than one with the victim of sexual assault demonstrating competency (Antaki and Stokoe 2017; Stokoe, Edwards and Edwards 2015). P's yes-no interrogative questions (Raymond 2003) about W's intention to tell the truth receive a preferred response ("yeah") at line 5. However, unlike the confirmatory "yes" responses in prior extracts, this is just the beginning of multiple turns that continue to extend the sequence:

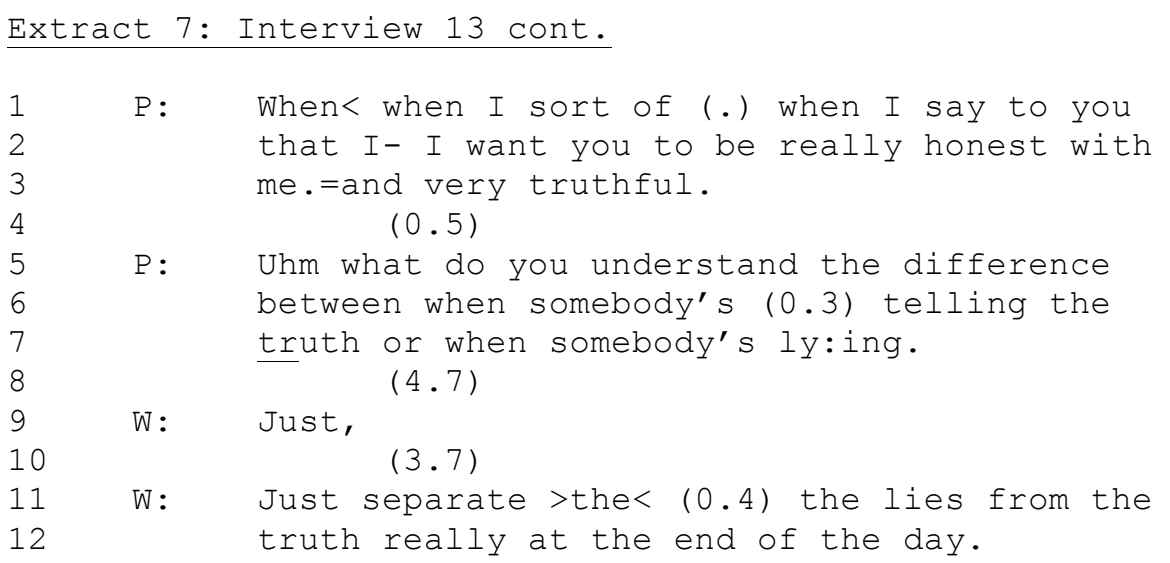

At line 12, by concluding their answer with an idiomatic expression ("at the end of the day") it seems that W has nothing more to add (see Drew and Holt 1988). Furthermore, we know 
that when one interlocutor repeats the same question, recipients may infer that they have given the wrong answer (e.g., Macbeth 2004). Across Extracts 5 to 7 - with more material we do not have space to present - the possibility that $\mathrm{W}$ may feel that $\mathrm{P}$ does not believe they will tell the truth, or understand it, seems real. In Extract 8, we see the final iteration of the sequence before $\mathrm{P}$ moves on to a new topic.

\section{Extract 8: Interview 13 cont.}

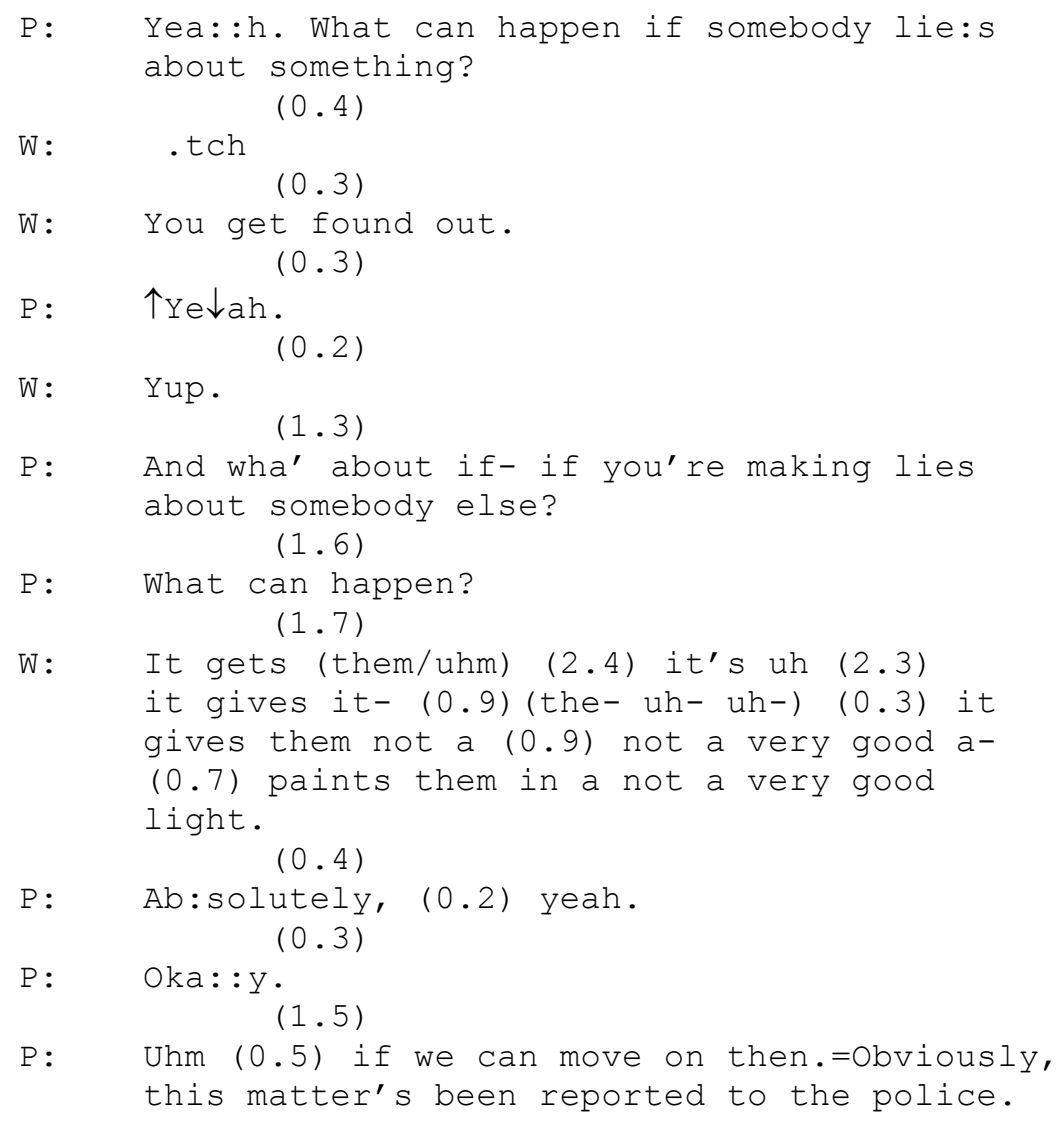

P's questions now focus on eliciting from $\mathrm{W}$ that he is able to demonstrate an understanding of what "lying" means, in particular, across two question-answer sequences ("what can happen if somebody lies about something?"; "what about if you're making lies about somebody else?'). At line 23, P confirms that W has answered 'correctly' and the interview moves on.

By eliciting multiple demonstrations and confirmations of understanding from $\mathrm{W}$, this sequence is markedly extended beyond the 'best practice' that is provided for by ABE. As we 
suggested earlier, the overall sequence is more akin to a suspect than a witness interview where follow-up questions are more common place (Antaki and Stokoe 2017). Indeed, when we presented these data to the police officers who deliver interview training, this was their own assessment. However, the 'truth and lies' conversation was still located correctly at the start of the interview, before a narrative account of events is elicited. In the final section, we examine cases in which talk about truth and lies is re-introduced at other phases of the interview.

\section{When truth and lies discussions are re-initiated}

$\mathrm{ABE}$ guidelines state that questions about truth telling should not happen "later in the interview because this might run the risk of the [witness] concluding that the interviewer had not believed what they had said up to that point" (p.72). However, in our first example, it is the witness who invokes truth and lies. We re-join Interview 13 as $\mathrm{P}$ questions $\mathrm{W}$ about their account, and they are talking about the alleged perpetrator's penis.

\section{Extract 9: Interview 13 cont.}

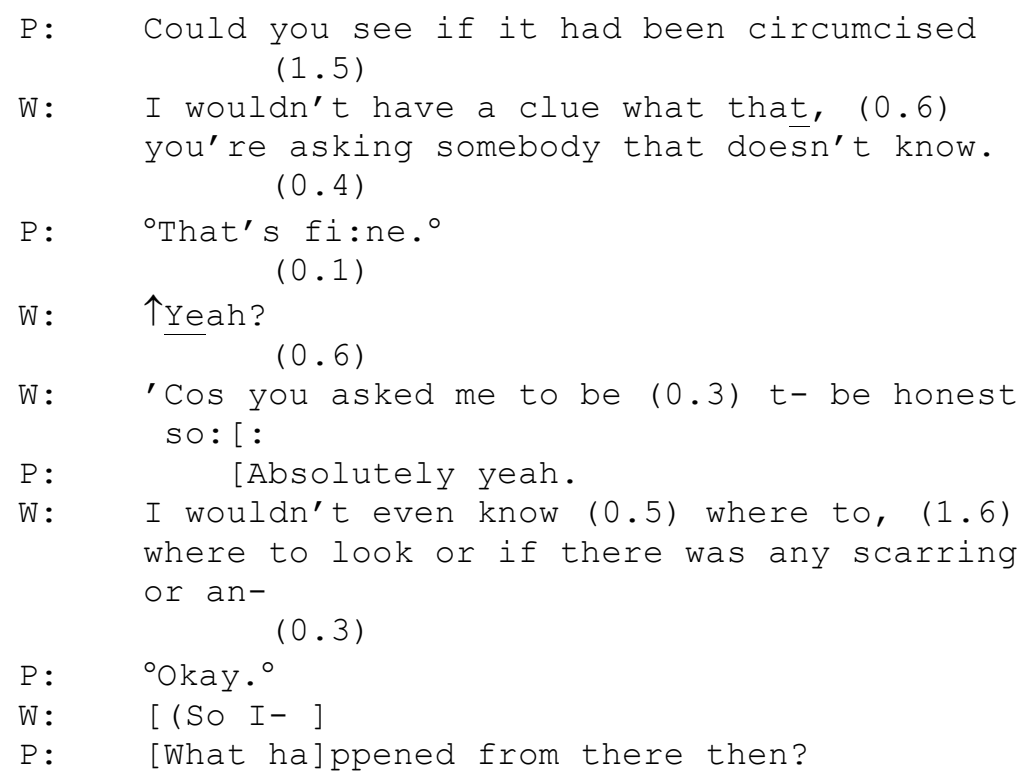


Prior to this extract, $\mathrm{W}$ has been providing $\mathrm{P}$ with a detailed account of the alleged perpetrator's actions. P asks “Could you see if it had been circumcised?" W produces a dispreferred response, after some delay, between lines 4 and 6, which accounts for the lack of type-conforming (yes or no) response. W states that he "wouldn't have a clue what that", then abandons and restarts his response: “you're asking someone that doesn't know". P does not pursue the topic even though expansion is relevant, and does not, say, check W's understanding of the term 'circumcised'. Instead, P moves to close the sequence at line 8 with a softly-produced “that's fine”. W treats P's lack of pursuit of a response as accountable, and he invokes 'being honest' as a resource ("Cause you asked me to be honest"). In so doing, W presses the point that he cannot answer, rather than that he is being uncooperative.

In Extract 10, the police officer initiates discussion of truth and lies - well outside the opening phase of the interview and counter to ABE guidelines. $\mathrm{P}$ is questioning $\mathrm{W}$ about their use of pornography.

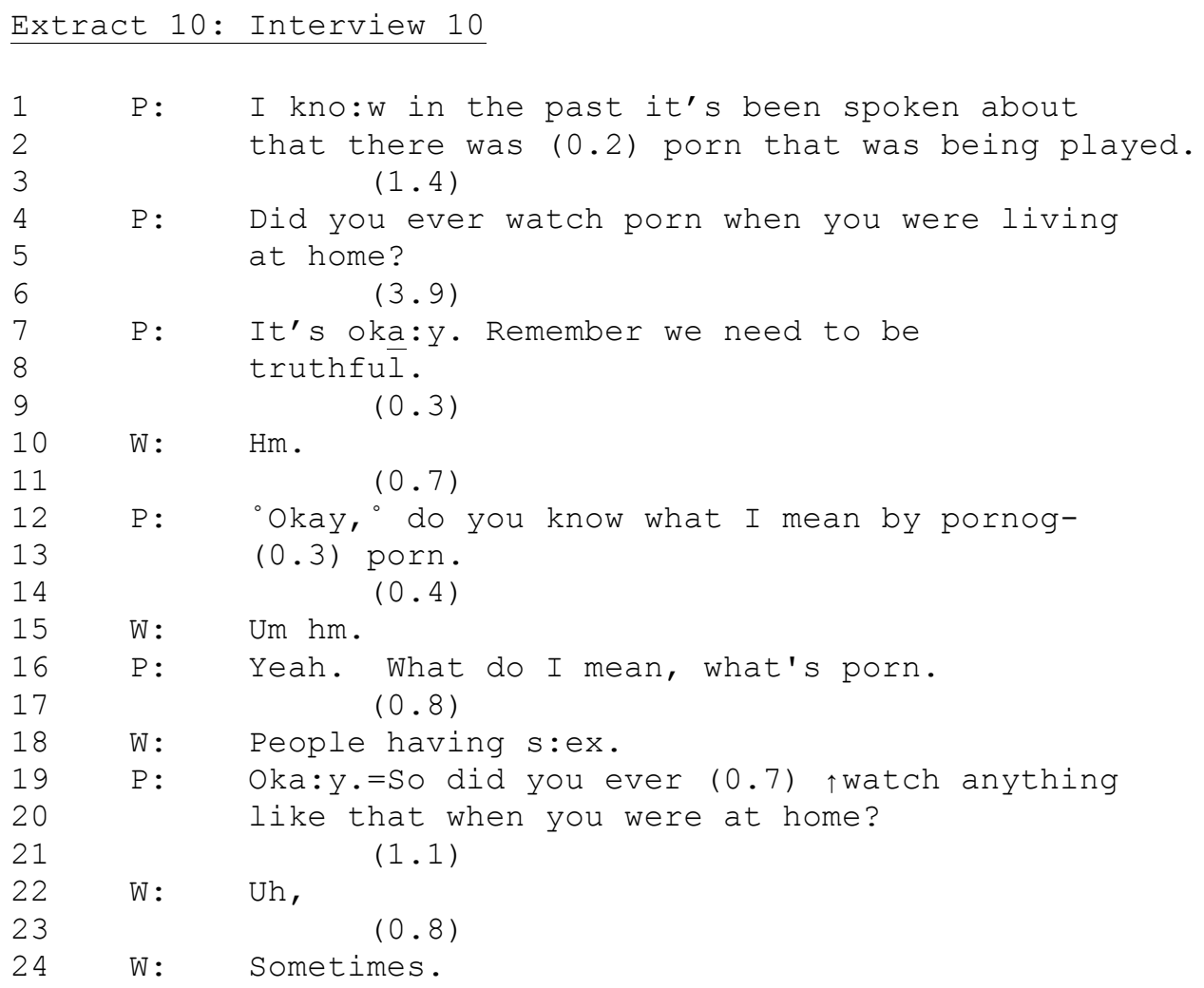


When $\mathrm{P}$ asks if $\mathrm{W}$ ever watched porn at home, the long 3.9 second gap indicates interactional trouble. P treats this silence as W's reluctance to 'be truthful' about this topic (and that she already knows the answer to the question). Instead of repeating or reformulating her question, and implying that W's lack of response comes from trouble in hearing or understanding, $\mathrm{P}$ reassures W ("It's okay") and then reminds her that "we need to be truthful" (lines 7-8). This elicits a minimal response from W at line 10 ("Hm"). P treats this as a renewed display of truth-telling intent from $\mathrm{W}$, and proceeds now by treating W's earlier lack of response as a potential misunderstanding of what pornography is (line 12-16). When W confirms that they do know what it is, $\mathrm{P}$ reissues the questions in relation to $\mathrm{W}$ watching porn at home. With some delay, W confirms that she "sometimes" (line 24) does.

While the re-introduction of 'truth and lies' occurs beyond its formal location at the start of the interview, it may be used effectively to elicit a response from witnesses, in tandem with reassurance when answering a delicate question. We rejoin the interview a few minutes later.

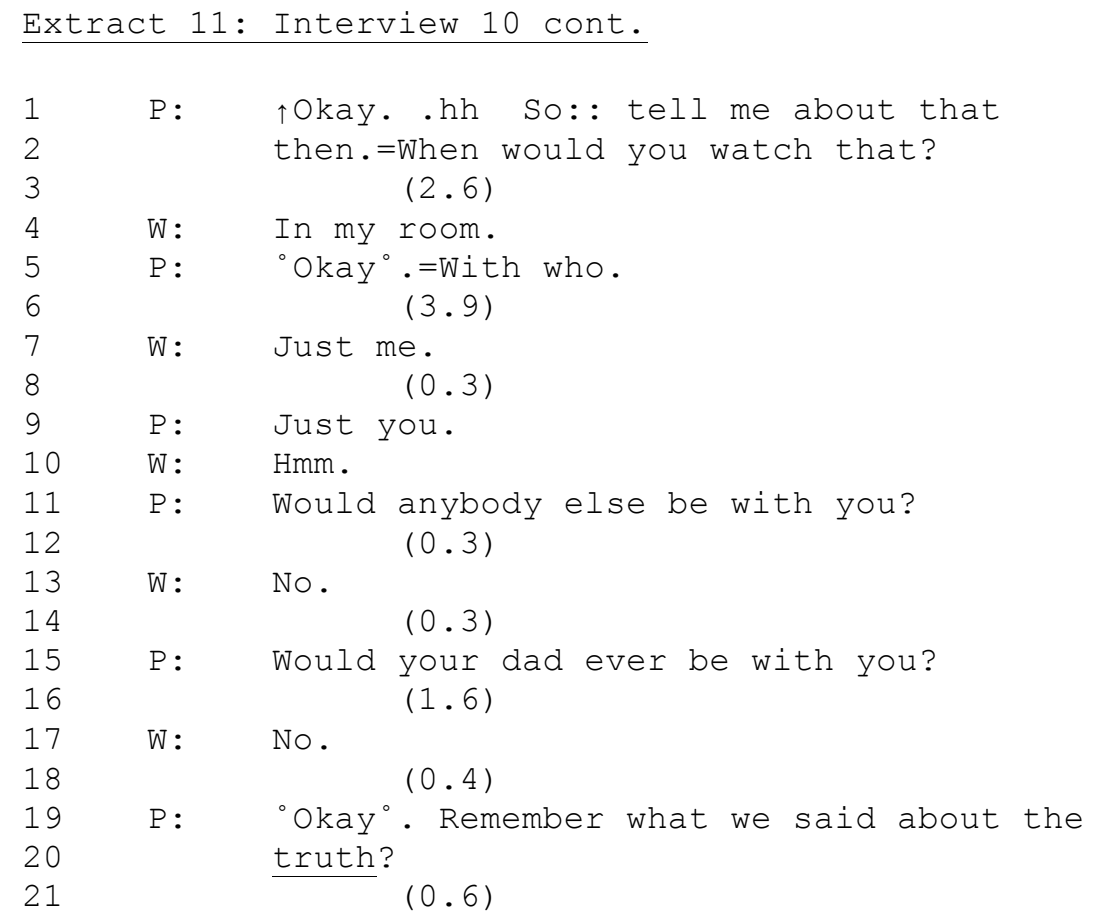




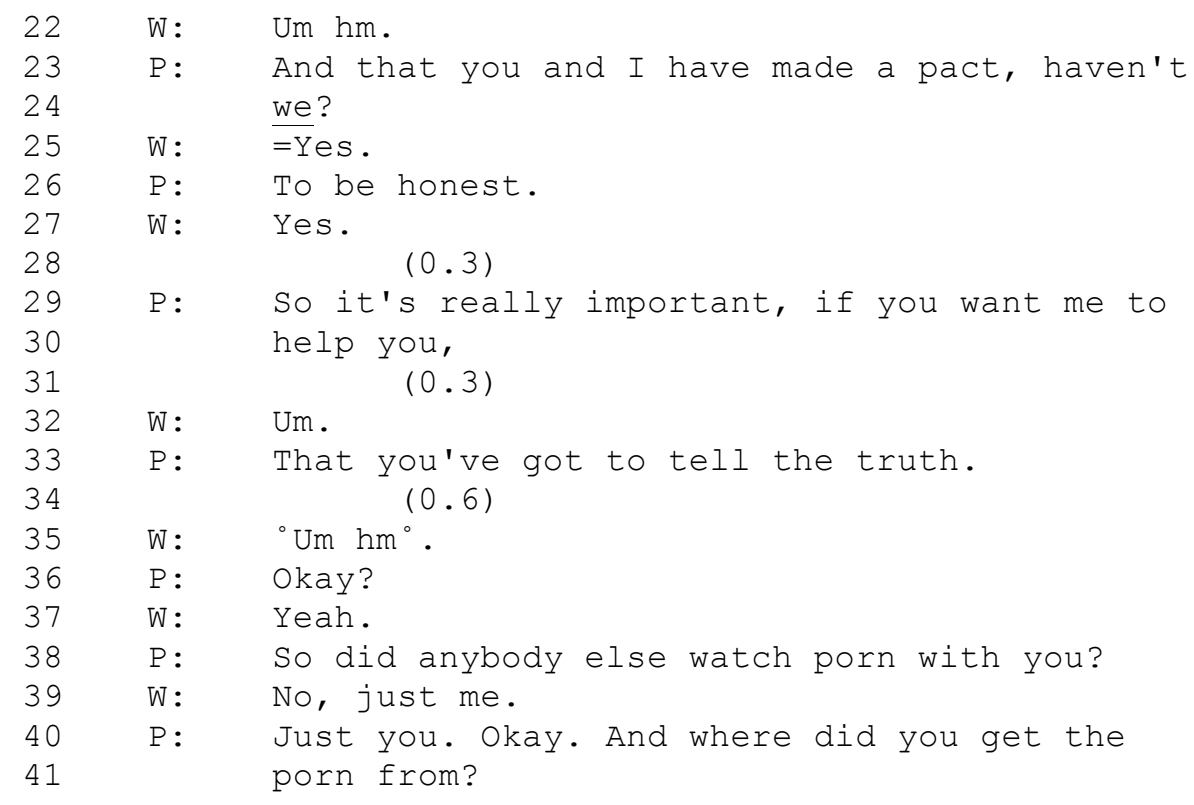

$\mathrm{P}$ asks a series of questions about who, if anyone, watched pornography with $\mathrm{W}$. W states that she watched it alone, on five occasions, in various formats. P's first question "with who" (line 5), implies that $\mathrm{W}$ did not watch porn alone. The 3.9 second gap before $\mathrm{W}$ answers, "Just me", while delayed, is a preferred response and a clear, complete answer. P repeats W's answer, but not as a sequence-closing third turn - it is delayed, and $\mathrm{W}$ treats it as a confirmation check. W confirms again that she watched alone, yet P treats this answer as non-cooperative (see Antaki and Stokoe 2017) by asking a second version of the question: "Would anyone else be with you". W's "no" answer confirms her two previous responses. P asks a further question about the same activity: "Would your dad ever be with you?"; W maintains the same response. P's multiple questions imply that W's answers have not been heard, are insufficient, or are lies. P then reintroduces the 'truth and lies sequence', which heavily implies that W's previous answers were lies (lines 19-37). When she reissues the final question at line $38, \mathrm{~W}$ provides the same answer she did from the start of the sequence.

In our final example, $\mathrm{P}$ reintroduces a truth and lies question at the end of the interview. 


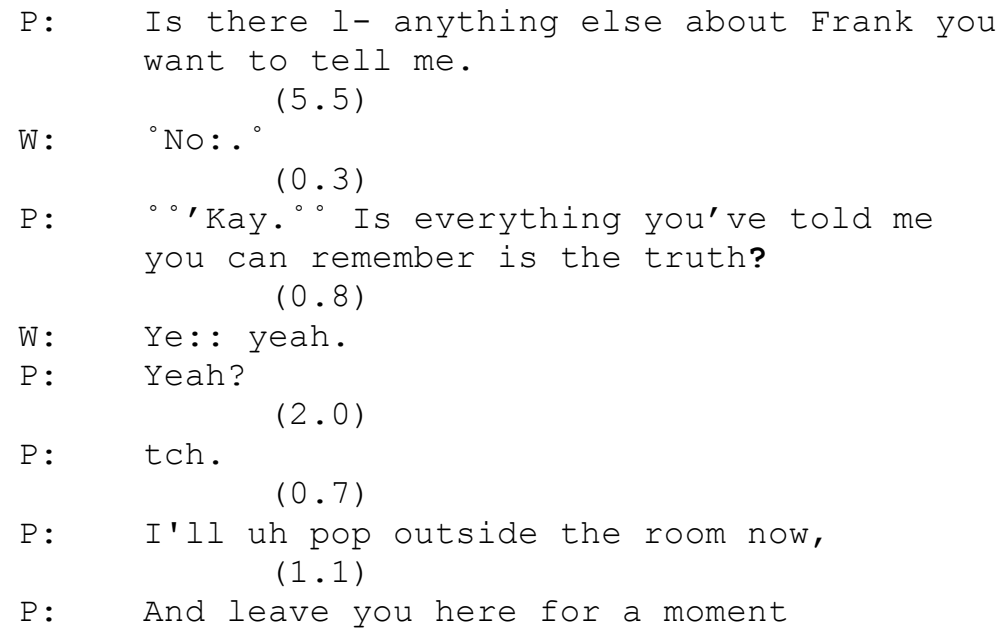

P's question requires W to confirm that "everything" she has said in the interview is "the truth", which W does, after a delay. P appears to pursue a second confirmation (line 10), but no answer is forthcoming from $\mathrm{W}$, and $\mathrm{P}$ concludes this phase of the interview.

We have seen that, when 'truth and lies sequences' occur outside the formal opening phase of the interview, they accomplish a variety of functions other than the mandated $A B E$ demonstration of understanding. When witnesses participate in extended sequences around truth and lies the implication is that the account is being perceived as dishonest, running counter to the aim of creating "an environment that [victims] feel at ease, listened to, and not judged" (Westera et. al. 2016: 1750; emphasis added). Similarly, witnesses who are not given any opportunity to demonstrate (or confirm) their understanding, may nevertheless find themselves being asked about truth and lies after they have already answered officers' questions. Officers may also ask the witness to confirm they have been telling the truth at the close of the interview. In the pursuit of creating a safe and encouraging environment for victims of sexual assault, our analysis has focused on just one way in which interview practices may, in fact, create the opposite. 


\section{Discussion}

This study examined how police officers 'achieved best evidence' when asking vulnerable victims of sexual assault about their understanding of truth and lies in the wider context of underreporting rape, and the prevalence of rape myth. We know that effective police interviews are central to the legal process for victims of sexual assault, but very little is known about the actual communication that occurs between police officers and witnesses and the alignment between guidance and real practice.

Our analysis revealed that interviewers initiated conversation about truth and lies appropriately, but also inappropriately in three ways: 1) by eliciting confirmations rather than demonstrations of understanding; 2) by eliciting multiple demonstrations and confirmations of understanding, or 3) by re-introducing questions about truth and lies in parts of the interview deemed inappropriate according to the guidance. Both 2) and 3) imply prior or forthcoming dishonesty on the part of the witness. By eliciting confirmations rather than demonstrations, police interviewers breach best practice guidelines. Furthermore, because the goal of the guidance is to elicit witnesses' demonstrations of their understanding, as part of evidence-giving and relevant to later court proceedings, failure to do may not be in the best interests of the victim. If witnesses do not, for the record, display their understanding of 'truth and lies', subsequent evidence may be regarded as less robust.

While officers elicit multiple demonstrations and confirmations of understanding from witnesses, the practice of repeating questions implies previously insufficient, incorrect or, in this context, dishonest answers. These types of multiple questioning sequences also move far beyond the 'best practice' provided for by the guidance, and are akin to suspect rather than witness interviews. We found that when 'truth and lies sequences' occurred outside the formal opening phase of the interview, they accomplished a variety of functions other than the 
mandated ABE demonstration of understanding. Police officers' questions about witnesses' understanding of truth and lies, or intention to tell the truth, often appeared after witnesses had already answered officers' questions - implying that previous answers were not truthful.

We know that police services have come a long way to provide a safe and supportive context for alleged victims of sexual abuse. Clear guidance has existed for some time, when interviewing adults and children with intellectual impairments. But in the context of encouraging victims to report sexual assault, and achieve justice, we have identified a potential barrier in which victims - or their evidence - may be discredited right at the start of the criminal justice process when victims give their accounts to police officers. As Westera et. al. (2016: 1749) point out amongst many other commentators, "outcomes in rape investigations and prosecutions can improve through better utilization of police interviewing methods." The findings from this paper have implications for interviewing methods, which have focused on just one item in the 'Achieving Best Evidence' guidelines. Further research, using a larger dataset, may help unpack other parts of the guidelines in order to establish which are effective, which are followed, and which are abandoned. Analysis can also reveal the tacit expertise of interviews which does not currently appear in the guidance (see Stokoe and Sikveland 2017). Although we hesitate to bold recommendations at this stage, where there may be difficulties in turning research findings into practice, one thing that does bear emphasis is the danger of the interviewer issuing multiple warnings about 'telling the truth'. We hope this article pave the way for a systematic analysis of the many other components of police interviewing practice, and communication guidance, and their translation in actual interviews. 


\section{References}

Antaki. 2011. Applied Conversation Analysis: Intervention and Change in Institutional Talk. Palgrave Macmillan.

Antaki, C., Richardson, E., Stokoe, E., and Willott, S. 2015. 'Dealing with the distress of people with intellectual disabilities reporting sexual assault and rape,' Discourse Studies 17: 1-18.

Antaki, C. and Stokoe, E. 2017. 'When police treat straightforward answers as uncooperative,' Journal of Pragmatics 117: 1-15.

Armstrong, C. L., Hull, K. and Saunders, L. 2015. 'Victimized On Plain Sites; social and alternative media's impact on the Steubenville rape case,' Digital Journalism 4/2: 247 265.

Beail, N. 2002. 'Interrogative Suggestibility, Memory and Intellectual Disability,' Journal of Applied Research in Intellectual Disabilities 15/2: 129-137.

Brown, H., Stein, J. and Turk, V. 1995. 'The sexual abuse of adults with learning disabilities: Report of a second two-year incidence survey,' Journal of Applied Research in Intellectual Disabilities 8/1: 3-24.

Bull, R. 2010. 'The investigative interviewing of children and other vulnerable witnesses: psychological research and working/professional practice,' Legal and Criminal Psychology 15/1: 5-23.

Burman, M., Kelly, L. and Lovett, J. 2009. 'Different Systems, Similar Outcomes? Tracking Attrition in Reported Rape Cases in Eleven Countries,' University of North London, Child and Women Abuse Studies Unit.

Burt, M. R. 1980. 'Cultural myths and supports for rape,' Journal of Personality and Social Psychology 38: 217-230. 
Cederborg A. C. and Lamb, M. 2008. 'Interviewing alleged victims with intellectual disabilities,' Journal of Intellectual Disability Research 52/1: 49-58.

Clare, I. C. H. and Gudjonsson, G. H. 1993. 'Interrogative suggestibility, confabulation, and acquiescence in people with mild learning disabilities (mental handicap): Implications for reliability during police interrogations,' British Journal of Clinical Psychology 32: 295301.

Commission on Women and the Criminal Justice System. 2009. Engendering Justice: From Policy to Practice, Commission on Women and the Criminal Justice System.

Cooke, P. and Davies, G. 2001. 'Achieving best evidence from witnesses with learning disabilities: New guidance,' British Journal of Learning Disabilities 29/3: 84-87.

Crown Prosecution Service. 2017. Special Measures: Legal Guidance. Retrieved on $26^{\text {th }}$ February, 2018, from https://www.cps.gov.uk/legal-guidance/special-measures

Crown Prosecution Service. 2016. Violence against Women and girls: Crime Report 20152016. Retrieved on $31^{\text {st }}$ October, 2017, from $<\underline{\text { http://www.cps.gov.uk/publications/docs/cps vawg report 2016.pdf }>}$

Daly, K., and Bouhours, B. 2010. 'Rape and attrition in the legal process: A comparative analysis of five countries,' Crime and Justice: An Annual Review of Research 39: $565-$ 650.

Holt, E. and Drew, P. 1988. 'Complainable matters: the use of idiomatic expressions in making complaints, ' Social Problems 35/4: 398-417.

Drew, P. 1992. 'Contested evidence in courtroom cross-examination: The case of a trial for rape,' in Drew, P. and Heritage, J. (eds.): Talk at Work: Interaction in Institutional Settings. Cambridge University Press.

Ehrlich, S. 2001. Representing Rape: Language and Sexual Consent. Routledge.

Estrich, S. 1987. Real Rape. Harvard University Press. 
Gudjonsson, G.H. and Henry, L.A. 2003. 'Child and adult witnesses with learning disabilities: The importance of suggestibility,' Legal and Criminological Psychology 8: 241-252.

Hayes, R. M., Lorenz, K. and Bell, K. A. 2013. 'Victim blaming others: Rape myth acceptance and the Just World Belief,' Feminist Criminology 8/3: 202-220.

Houtkoop-Steenstra, H. and Antaki, C. 1997. 'Creating happy people by asking yes-no questions,' Research on Language and Social Interaction, 30/4: 285-313.

Jordan, J. 2004. The word of a woman? Police, rape and belief. Palgrave Macmillan.

Kebbell, M. R., Hatton, C., Johnson S. D. and O'Kelly, C.M. E. 2001. 'People with learning disabilities as witnesses in court: what questions should lawyers ask?,' British Journal of Learning Disabilities 29/3: 98-101.

Kebbell, M. R. and Hatton, C. 1999. 'People with mental retardation as witnesses in court: A Review,' Mental Retardation 37: 179-187.

Kebbell M. R. and Milne, R. 1998. 'Police officers' perceptions of eyewitness performance in forensic investigations,' Journal of Social Psychology 138/3: 323-30.

Krahé, B. (2016). Societal responses to sexual violence against women: Rape myths and the "real rape" stereotype. In Kury H., Redo S., Shea E. (Eds.), Women and children as victims and offenders: Background, prevention, reintegration (pp. 671-700). Springer, Cham. DOI https://doi.org/10.1007/978-3-319-08398-8 24

Lea, S., Lanvers, U. and Shaw, S. 2003. 'Attrition in rape cases: developing a profile of identifying relevant factors,' British Journal of Criminology 43: 583-599.

Lonsway,A. K. and Fitzgerald, L. F. 1994. 'Rape myths; in review,' Psychology of Women Quarterly 18/2: 133-164.

Macbeth, D. 2004. 'The relevance of repair for classroom correction.' Language in Society 33: $703-736$. 
MacLeod, N. J. 2010. Police Interviews with Women Reporting Rape: A Critical

DiscourseAnalysis, Unpublished PhD thesis, School of Languages and Social Sciences, Aston University. Retrieved on $31^{\text {st }}$ October, from < http://eprints.aston.ac.uk/15206/> Maynard, D. W. and Schaeffer, N. C. 2006. 'Standardization-in-interaction:The survey interview,' In Drew, P. Raymond G., Weinberg, D. (eds.): Talk and Interaction in Social Research Methods. Sage.

McEachern, A. G. 2012. 'Sexual abuse of individuals with disabilities: Prevention strategies for clinical practice,' Journal of Child Sexual Abuse 21: 386-398.

Office for National Statistics. 2017. Compendium: Overview of violent crime and sexual offences. Retrieved October $31^{\text {st }}, 2017$, from $<$ https://www.ons.gov.uk/peoplepopulationandcommunity/crimeandjustice/compendiu $\underline{\mathrm{m} / \text { focusonviolentcrimeandsexualoffences/yearendingmarch2016/overviewofviolentcri }}$ $\underline{\text { meandsexualoffences\#what-do-we-know-about-sexual-offences> }}$

Petersilia, J. R. 2001. 'Crime victims with developmental disabilities: A review essay,' Criminal Justice and Behavior 28: 655-694.

Stokoe, E. 2013. 'The (in)authenticity of simulated talk: Comparing role- played and actual interaction and the implications for communication training,' Research on Language and Social Interaction 46/2: 165-185.

Stokoe, E., Edwards, D., \& Edwards, H. 2015. “"No comment” responses to questions in police investigative interviews'. In S. Ehrlich, D. Eades \& J. Ainsworth (Eds.), Coercion and consent in the legal process: Linguistic and discursive perspectives. Oxford: Oxford University Press.

Stokoe, E. \& Sikveland, R.O. (2017). The Conversation Analytic Role-play Method: Simulation, endogenous impact and interactional nudges. In V. Fors, T. O’Dell \& S. 
Pink (Eds.), Theoretical scholarship and applied practice. Oxford: Berghahn Books. ISBN 978-1-78533-416-0.

Parratt, K. A. and Pina, A. 2017. 'From "real rape" to real justice: A systematic review of police officers' rape myth beliefs,' Aggression and Violent Behavior 34: 68-83.

Raymond, G. 2003. 'Grammar and social organization: Yes/no interrogatives and the structure of responding.' American Sociological Review 68/6: 939-967.

Schegloff, E. A. 2007. 'Sequence organization in interaction: Volume 1: A primer in conversation analysis’. Cambridge University Press.

Stokoe, E. 2013. 'The (in)authenticity of simulated talk: Comparing role-played and actual conversation and the implications for communication training,' Research on Language and Social Interaction 46/2: 1-21.

Taylor, S. C. and Gassner, L. 2010. 'Stemming the flow: Challenges for policing adult sexual assault with regard to attrition rates and under-reporting of sexual offences,' Police Practice and Research, 11/3: 240-255.

Temkin, J., Gray, J.G., \& Barrett, J. (2018). Different Functions of Rape Myth Use in Court: Findings From a Trial Observation Study. Feminist Criminology, 13 (2), 205-226.

U.K. Ministry of Justice. 2011. Achieving Best Evidence in Criminal Proceedings: Guidance for Vulnerable or Intimidated Witnesses, including Children. Ministry of Justice. Retrieved on $31^{\text {st }}$ October, 2017, from $<$ https://www.cps.gov.uk/publications/docs/best_evidence_in_criminal_proceedings.pd f>

Westera, N. J., Kebbell, M. R. and Milne, R. 2016. 'Want a better criminal justice response to rape? Improve police interviews with complainants and suspects,' Violence Against Women 22/14:1748-1769. 